\title{
Methods used to conduct the pan-European Union survey on consumer attitudes to physical activity, body weight and health
}

\author{
JM Kearney, M Kearney, S McElhone and MJ Gibney \\ Institute of European Food Studies, Trinity College, Dublin 2, Ireland
}

\begin{abstract}
Objective: The purpose of conducting this survey was to identify data on consumer attitudes towards and beliefs about physical activity, body weight and health among the 15 countries of the EU.

Design: A cross-sectional study to get a picture of the attitudes to physical activity, body weight and health in the EU. For this, it was considered important that samples be nationally representative so that inferences drawn from the data could be applied to the population in each country as well as to the EU population as a whole. Using a non-probability sampling method employing quota controls (and the national weight) we obtained large sample sizes from each country which were nationally representative in terms of the variables age, sex and regional distribution. To ensure samples were truly nationally representative a national weight was used when analysing the data using the same characteristics as those used to define quotas. When examining pooled estimates for the total EU sample a population weight was applied. Results: In total, 15239 subjects aged 15 years and upwards in the EU completed the survey. This article gives details on the methods used in carrying out the survey from design of the questionnaire to sample selection, questionnaire administration and analysis of the data. The methods and their limitations are discussed.
\end{abstract}

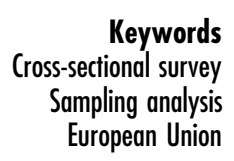

The purpose of conducting this survey was to identify data on consumer attitudes towards, and beliefs about, physical activity, body weight and health among the 15 countries of the EU. Data on the sociocultural and demographic differences in such attitudes will help those involved in the promotion of physical activity in the general population to develop more focused and effective campaigns. This article gives details on the methods used in carrying out the survey from the design of the questionnaire to sample selection, questionnaire administration and analysis of the data, all of which were similar to those used in an earlier pan-EU survey of consumer attitudes to food, nutrition and health ${ }^{1}$. Subsequent articles covering different issues from the survey will provide more details on the specific questions and their particular analyses.

\section{Questionnaire design}

A project management group developed the questionnaire. This group consisted of scientists from each member state and representatives from the food industry along with members of the Institute of European Food Studies (Appendix 1). A workshop was held to design the questionnaire firstly by reviewing existing studies on attitudes and secondly reviewing the methodology for measuring physical activity in large population surveys. The specific objectives of this pan-EU survey were as follows.

- To identify the main attitudes to physical activity/ exercise, body weight and health in different countries in the EU and among different sociodemographic groups.

- To examine the motivating factors and perceived barriers to participating in physical activity/exercise.

- To determine the current levels of participation (self-reported) in leisure-time physical activity/ exercise in the EU.

- To examine the current levels of activity/inactivity at work (self-reported).

- To determine the proportion of people who are underweight, normal weight, overweight and obese in the EU based on self-reported weights and heights. Also, to determine the proportion claiming to have changed weight in the 6 months previous to the survey and the methods employed to achieve this weight change.

- To examine current and ideal body image in the EU.

Caspersen $e t a l^{2}$ have clearly distinguished the terms physical activity, exercise and sport. For the purpose of this survey the Project Management Group decided that the terms 'physical activity/exercise' should be used in 
conjunction throughout the questionnaire, thereby enabling respondents to think of leisure-time activities in their broadest sense. For this reason the term sport was purposely avoided because it has a more limited definition ${ }^{2}$. The timing and duration over which the survey was to be conducted throughout the 15 countries in the EU was also considered. Since participation in different leisure-time activities varies according to the season in each country it was important that the survey be conducted during the same time period in all countries and over as short a period as possible.

The final questionnaire included 12 close-ended questions and, where possible, previously validated questions were used. In addition, further information was sought from respondents on various sociodemographic characteristics. Care was taken to ensure that the data on demographic variables were comparable by collecting standardized information from respondents in the 15 member states. Information on the following sociodemographic variables was collected, being common to all 15 member states.

1. Sex $=$ male or female

2. Age (years) $=15-24 ; 25-34 ; 35-44 ; 45-54 ; 55-64$; $65+$.

3. Education $=$ highest level of education achieved by respondent: primary; secondary; tertiary.

4. Marital status = single; married/cohabiting; widowed/ separated.

5. Number of subjects in the household $=1 ; 2 ; 3 ; 4 ; 5+$. 6. Number of children in the household $=0 ; 1 ; 2 ; 3+$. 7. Region $=$ country-specific region.

Information on social class was also collected from respondents. However, since the criteria for defining social class differs between countries (in Denmark, Sweden, Finland, Germany and the Netherlands it is based on personal or household income, while in the other 10 member states it is based on occupation of respondent (or head of household)) it is difficult to standardize this variable. Therefore, social class could not be used comparatively across member states. Instead, for comparisons between countries, the variable 'education' (highest education level attained) was used as a measure of 'social class'.

The finalized questionnaire was translated from English into all relevant languages. These were then checked by the Project Management Group and piloted on a sample of 20 subjects in each country to ensure they had retained their original sense.

\section{Sample selection}

A market research organization, MRBI Ltd, was responsible for coordinating the fieldwork in this study. They subcontracted the survey to market research organizations operating in each member state who were involved in selecting the sample and conducting the interviews in each country (Appendix 2). All of these research organizations were members of the 'Eurobus' network operating to the same standards and procedures of marketing research set out by ICC/ESOMAR ${ }^{3}$. 'Eurobus' is an international group of market research organizations offering market research in all 15 member states for the purposes of carrying out cross-country surveys. An omnibus approach was used whereby respondents answer questions on several different topics from various clients in the same interview. Such surveys are frequently conducted by clients from industry to follow market trends.

The aim in this survey was to recruit nationally representative samples from each member state of approximately 1000 adults (age 15 years or more). The target sample was smaller in Luxembourg $(n=500)$ and largest in the UK $(n=1250$ of which 250 were sampled from Northern Ireland) and Germany ( $n=1250$ of which 250 were from former East Germany and 1000 from former West Germany). Multistage stratified cluster sampling was used with quotas applied on samples in each country to ensure that they were nationally representative. The procedure involved each country being divided up into a certain number of regions or strata where the number of primary sampling units assigned to each stratum was proportional to the population size of each stratum. Sampling points (where actual subject selection occurs) were chosen from each sampling unit ${ }^{4}$. The number of sampling points and the procedure used to select subjects within sampling points in each country are shown in Table 1.

Since the objective in this survey was to collect nationally representative samples, quotas were used and defined in each country based on demographic factors using the most recent census data (official statistics) (Table 2). In all countries only one person per household was interviewed. In instances where there was more than one eligible person resident in a household different approaches were used in different countries to choose the person interviewed. In Denmark and Sweden, the 'next birthday' method was used; in Austria, the Kish grid was used ${ }^{5}$. In the remaining countries, the first eligible person to answer the door was interviewed. Within each area, names were randomly selected from the electoral register. If a named individual was not available, another subject was selected using the random route method ${ }^{6}$.

An in-house face-to-face interview-assisted technique was used to administer the questionnaire in all countries. Flash cards containing the various response options were used. Care was taken to ensure that any 


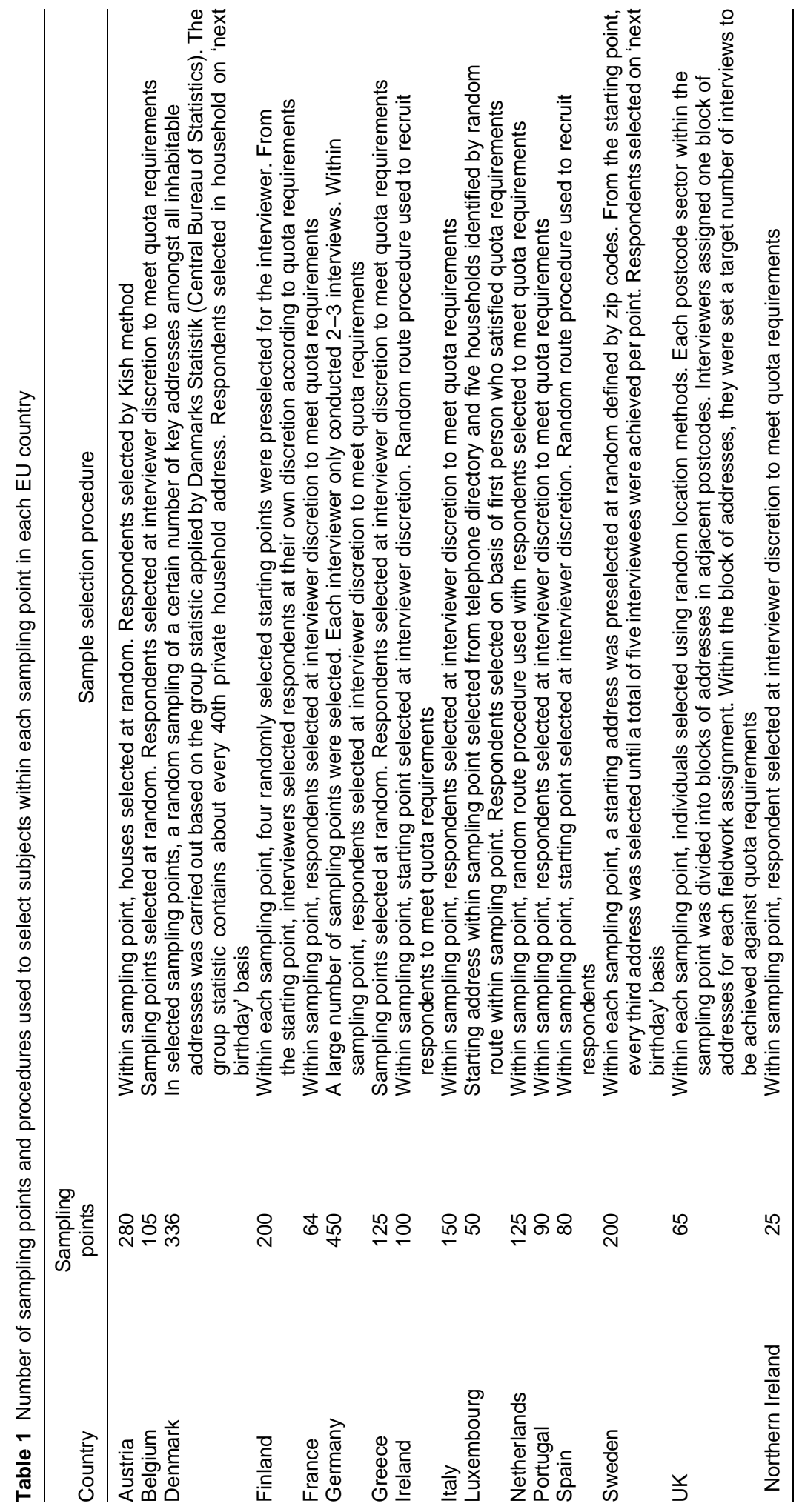




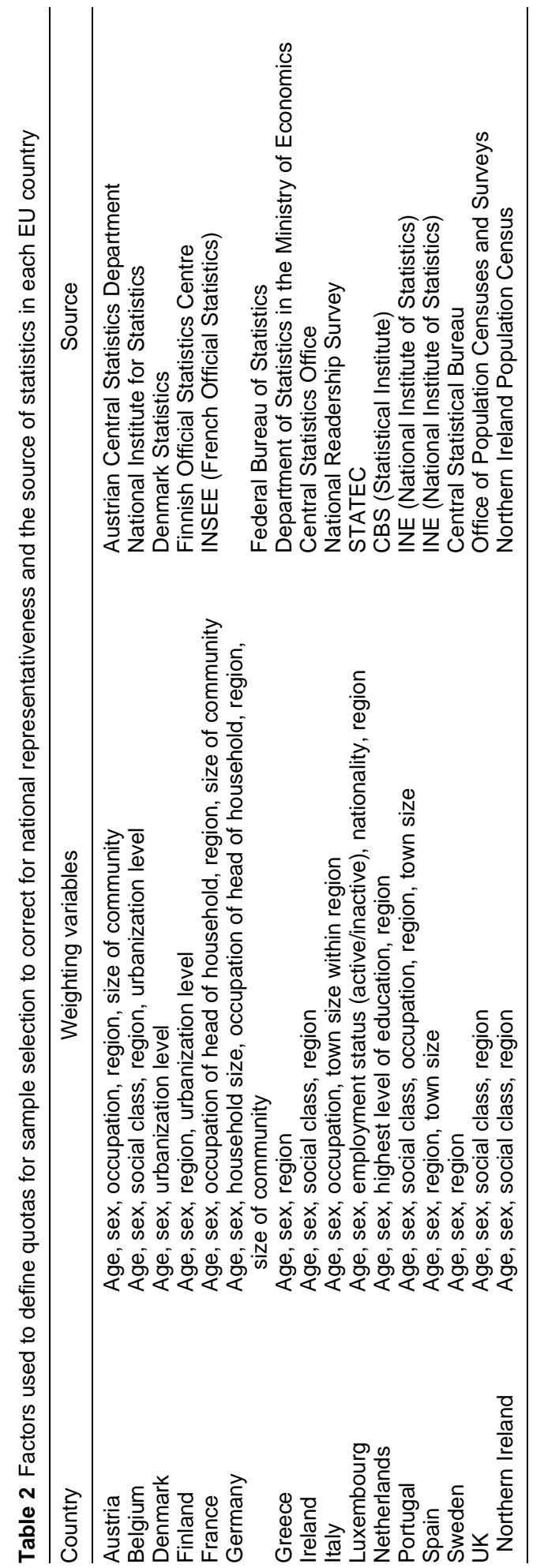

possible bias resulting from people selecting the first option on the list was avoided by sequentially reversing the order of options of the questions. Standard checking procedures of at least 10\% call back in each country was used.

\section{Analyses of data}

Data entry was conducted by the market research organization which had carried out the fieldwork in each country. This was then checked by the coordinating research organization, MRBI (Ireland), before being merged into tab-delimited ASCII files and a format suitable for analysis by the statistical package for social sciences (SPSS) for Windows (version 8.0). In addition to the samples in each country being quota-controlled to make them nationally representative, responses were also weighted by demographic factors for each sampling point based on the official statistics in each country. These were the same factors as those that had been used in defining the quotas (Table 2). In Italy, the sample was weighted according to the most recent national readership survey of more than 36000 randomly selected subjects. In any analyses of the data involving intercountry comparison, this national weighting was used. For analyses of the 'pooled' EU results, the national weighting was combined with a correction factor to account for population size, which differs considerably between the 15 EU countries (Table 3). Such a weight was important to ensure that responses from countries with smaller populations did not unduly influence the pooled results leading to biased estimates since the same sample size was selected in all countries (except Luxembourg).

Owing to the large sample size, even small differences (in the order of 2-3\%) between groups were highly statistically significant $(P<0.0001)$. Greater emphasis was placed on a descriptive, rather than a formal statistical, analysis of the data by highlighting marked differences in attitudes towards physical activity as they related to various sociodemographic and cultural factors, where they would be of use in the promotion and maintenance of a physically active lifestyle. For the purpose of this survey differences in the range of 10\% between groups were considered by the Project Management Group to be important.

\section{Results}

In total, 15239 subjects in the EU were surveyed. A response rate is not reported since sampling was by non-probability methods. The sociodemographic profile for the respondents in each of the 15 countries is shown in Table 4. Interviews in all countries were completed in a 2-month period between March and the end of April 1997. Within each member state interviews 
Table 3 Weighting factors for population size based on the adult population $(15$ years +$)$ in each EU country

\begin{tabular}{lc}
\hline Country & Population 15+ (in 000's) \\
\hline Austria & 6593 \\
Belgium & 8307 \\
Denmark & 4329 \\
Finland & 4130 \\
France & 46416 \\
Germany & 68493 \\
Greece & 8668 \\
Ireland & 2685 \\
Italy & 48679 \\
Luxembourg & 334 \\
Netherlands & 12648 \\
Portugal & 8128 \\
Spain & 32517 \\
Sweden & 7141 \\
UK (including Northern Ireland) & 47379 \\
Total & 306447
\end{tabular}

were conducted within an approximately 2-week period. Table 5 outlines the start and finish dates in the 15 member states.

\section{Discussion}

The principal aim of this cross-sectional study was to get a picture of the attitudes to physical activity, body weight and health in the EU and among each of the 15 countries in the EU. For this, it was considered important that samples be nationally representative so that inferences drawn from the data could be inferred to the population in each country as well as to the EU population as a whole. With the non-probability sampling method, using quota controls (and national weighting), we obtained large samples from each country which were nationally representative, at least in terms of the known characteristics such as age, sex and regional distribution. To ensure samples were truly nationally representative a national weighting was used when analysing the data using the same characteristics as those used to define quotas. When examining pooled estimates for the total EU sample a population weighting was applied to avoid bias due to population size differences between countries with smaller countries getting undue emphasis. The non-probability sampling methods used in this survey prevent us from estimating a response rate.

Respondents in this survey were asked many additional questions on varying topics (depending on the clients who were involved in which particular omnibus survey). Furthermore, participants were not aware at the outset when the interviewer began the survey that was about physical activity, body weight and health. This considerably reduces the possibility for greater participation among the more healthconscious segments of the population, which might arise if volunteers were asked to participate. This is a problem which can affect many health attitude surveys and limits the extrapolation of such findings to the general population.

Because we were particularly interested in crosscountry comparisons with regard to attitudes about physical activity it was important that methods of sampling, interviewing and coding be standardized to ensure comparability of the data. One of the advantages of omnibus research is that interviewers are fully trained to the same standards and that research organizations operating omnibus research conform to the same standards of marketing research. Another

Table 4a Sociodemographic profile of the subjects (\%) who participated in the pan-EU survey on consumer attitudes to physical activity, body weight and health: sex and age

\begin{tabular}{|c|c|c|c|c|c|c|c|c|c|}
\hline \multirow[b]{2}{*}{ Country } & \multirow[b]{2}{*}{ No. } & \multicolumn{2}{|c|}{ Sex } & \multicolumn{6}{|c|}{ Age (years) } \\
\hline & & Male & Female & $15-24$ & $25-34$ & $35-44$ & $45-54$ & $55-64$ & $65+$ \\
\hline Austria & 931 & 44 & 56 & 12 & 18 & 17 & 16 & 19 & 18 \\
\hline Belgium & 982 & 50 & 50 & 17 & 22 & 18 & 15 & 14 & 14 \\
\hline Denmark & 1147 & 48 & 52 & 14 & 18 & 19 & 18 & 12 & 19 \\
\hline Finland & 979 & 48 & 52 & 17 & 20 & 20 & 19 & 12 & 12 \\
\hline France & 1003 & 48 & 52 & 16 & 25 & 24 & 18 & 17 & NA \\
\hline Germany & 1159 & 48 & 52 & 13 & 23 & 20 & 17 & 21 & 6 \\
\hline Greece & 1011 & 44 & 56 & 23 & 21 & 21 & 13 & 13 & 9 \\
\hline Ireland & 1001 & 50 & 50 & 22 & 20 & 17 & 15 & 14 & 12 \\
\hline Italy & 1000 & 48 & 52 & 21 & 19 & 18 & 16 & 15 & 11 \\
\hline Luxembourg & 518 & 44 & 55 & 18 & 18 & 22 & 18 & 12 & 12 \\
\hline Netherlands & 1010 & 47 & 53 & 15 & 21 & 23 & 20 & 14 & 8 \\
\hline Portugal & 1007 & 46 & 54 & 20 & 20 & 16 & 16 & 13 & 15 \\
\hline Spain & 1000 & 52 & 48 & 22 & 20 & 16 & 12 & 12 & 18 \\
\hline Sweden & 1001 & 43 & 57 & 21 & 20 & 17 & 20 & 11 & 10 \\
\hline $\begin{array}{l}\text { UK (including } \\
\text { Northern Ireland) }\end{array}$ & 1490 & 46 & 54 & 12 & 19 & 20 & 15 & 13 & 20 \\
\hline EU weighted * & 15239 & 49 & 51 & 17 & 20 & 19 & 15 & 17 & 12 \\
\hline
\end{tabular}

NA, not asked.

* Weighted according to population size. 
Table 4b Sociodemographic profile of the subjects (\%) who participated in the pan-EU survey on consumer attitudes to physical activity, body weight and health: education level and marital status

\begin{tabular}{|c|c|c|c|c|c|c|c|}
\hline \multirow[b]{3}{*}{ Country } & \multirow[b]{3}{*}{ No. } & \multirow{2}{*}{\multicolumn{3}{|c|}{ Education level }} & \multicolumn{3}{|c|}{ Marital status } \\
\hline & & & & & & & Widowed/ \\
\hline & & Primary & Secondary & Tertiary & Single & Married & separated \\
\hline Austria & 931 & 29 & 50 & 21 & 24 & 62 & 14 \\
\hline Belgium & 982 & 12 & 67 & 21 & 24 & 62 & 14 \\
\hline Denmark & 1147 & 71 & 23 & 6 & 20 & 62 & 18 \\
\hline Finland & 979 & 33 & 57 & 10 & 23 & 62 & 15 \\
\hline France & 1003 & 17 & 56 & 27 & 36 & 52 & 12 \\
\hline Germany & 1159 & 48 & 37 & 15 & 19 & 69 & 12 \\
\hline Greece & 1011 & 27 & 52 & 21 & 33 & 62 & 5 \\
\hline Ireland & 1001 & 20 & 62 & 18 & 34 & 58 & 8 \\
\hline Italy & 1000 & 17 & 70 & 13 & 37 & 55 & 8 \\
\hline Luxembourg & 518 & 34 & 45 & 18 & 24 & 65 & 11 \\
\hline Netherlands & 1010 & 6 & 74 & 20 & 22 & 68 & 10 \\
\hline Portugal & 1007 & 60 & 29 & 11 & 28 & 62 & 10 \\
\hline Spain & 1000 & 63 & 25 & 12 & 33 & 59 & 8 \\
\hline Sweden & 1001 & 32 & 42 & 26 & 46 & 54 & NA \\
\hline $\begin{array}{l}\text { UK (including } \\
\text { Northern Ireland) }\end{array}$ & 1490 & 6 & 71 & 23 & 56 & 28 & 16 \\
\hline EU weighted * & 15239 & 30 & 52 & 18 & 31 & 58 & 11 \\
\hline
\end{tabular}

NA, not asked.

*Weighted according to population size

advantage of omnibus research is that it permits the sampling of large numbers of people in a relatively short period of time. Since interviews in all countries were conducted within a 6-week period (mid March to the end of April), this confined the period in question to one season. This is important because physical activity levels and types vary widely with season. It is only by doing this that we can reasonably compare responses between countries. In addition to the standardization of methods and the ability to survey large samples in short periods of time, omnibus surveys are relatively less costly as expenses are shared between a number of clients.
As well as the subjects' attitudes and perceptions to physical activity, body weight and health, self-reported measures of heights and weights, as well as physical activity (types and amounts) were also obtained. While, it would have been more desirable to actually measure heights, weights and physical activity, the costs of doing this would be prohibitive (for measures of height, weight and physical activity) and not possible using omnibus research (for measured levels of physical activity). However, since the aim of this baseline survey was to get a general picture of physical activity (attitudes and levels) and body weight (levels)

Table 4c Sociodemographic profile of the subjects (\%) who participated in the pan-EU survey on consumer attitudes to physical activity, body weight and health: number of children and total number of people in households

\begin{tabular}{|c|c|c|c|c|c|c|c|c|c|c|c|}
\hline \multirow[b]{2}{*}{ Country } & \multicolumn{5}{|c|}{ Number of children in household $<15$ years } & \multicolumn{6}{|c|}{ Number of people in household } \\
\hline & 0 & 1 & 2 & $3+$ & Missing & 1 & 2 & 3 & 4 & $5+$ & Missing \\
\hline Austria & 72 & 13 & 11 & 4 & - & 15 & 34 & 19 & 19 & 13 & - \\
\hline Belgium & 72 & 15 & 10 & 3 & - & 19 & 33 & 21 & 20 & 9 & - \\
\hline Denmark & 70 & 13 & 12 & 5 & - & 25 & 38 & 18 & 17 & 7 & - \\
\hline Finland & 63 & 16 & 14 & 7 & - & 22 & 35 & 19 & 17 & 7 & - \\
\hline France & 64 & 19 & 13 & 4 & - & 20 & 28 & 22 & 20 & 10 & - \\
\hline Germany & 68 & 17 & 12 & 3 & - & 14 & 37 & 25 & 17 & 7 & - \\
\hline Greece & 58 & 20 & 19 & 3 & - & 8 & 19 & 26 & 33 & 14 & - \\
\hline Ireland & 45 & 11 & 18 & 26 & - & 9 & 20 & 14 & 24 & 34 & - \\
\hline Italy & 74 & 16 & 8 & 2 & - & 7 & 18 & 30 & 31 & 14 & - \\
\hline Luxembourg & 60 & 22 & 13 & 5 & - & 11 & 24 & 20 & 28 & 17 & - \\
\hline Netherlands & 55 & 22 & 17 & 2 & 4 & 15 & 31 & 17 & 24 & 12 & 1 \\
\hline Portugal & 66 & 22 & 10 & 2 & - & 8 & 22 & 26 & 28 & 16 & - \\
\hline Spain & 68 & 20 & 9 & 3 & - & 7 & 20 & 22 & 28 & 23 & - \\
\hline Sweden & 70 & 12 & 12 & 6 & - & 28 & 33 & 18 & 14 & 7 & - \\
\hline $\begin{array}{l}\text { UK (including } \\
\text { Northern Ireland) }\end{array}$ & 63 & 15 & 14 & 8 & - & 17 & 30 & 20 & 20 & 13 & - \\
\hline EU weighted * & 65 & 17 & 13 & 5 & - & 15 & 28 & 21 & 22 & 13 & - \\
\hline
\end{tabular}

${ }^{*}$ Weighted according to population size. 
Table 5 Start and finish dates for interviews in the 15 member states

\begin{tabular}{ll}
\hline Country & Fieldwork dates \\
\hline Austria & 26 March -17 April \\
Belgium & 7 April -21 April \\
Denmark & 17 March -11 April \\
Finland & 25 March -4 April \\
France & 7 April -13 April \\
Germany & 25 March -2 April \\
Greece & 17 March -28 March \\
Ireland & 1 April -18 April \\
Italy & 24 March -18 April \\
Netherlands & 8 April -22 April \\
Portugal & 7 April -28 April \\
Spain & 10 March -23 March \\
Sweden & 31 March -8 April \\
UK (including Northern Ireland) & 17 March -8 April \\
\hline
\end{tabular}

and their inter-relationship across the different countries in the EU, self-reported measures were considered appropriate, particularly in view of the large sample size. While the body mass index (BMI) calculated from self-reported heights and weights may be slightly lower than that calculated from actual measurements due to overestimation of height and underestimation of weight ${ }^{8}$, in two countries (Italy and Sweden) recent studies of measured heights and weights gave similar BMI categories to those found in this survey ${ }^{9,10}$. Self-reported physical activity has been shown to determine adult activity patterns with moderate accuracy $^{11-13}$.

\section{References}

1 Kearney M, Kearney JM, Gibney MJ. Methods used to conduct the survey on consumer attitudes to food, nutrition and health on nationally representative samples of adults from each member state of the European Union. Eur.J. Clin. Nutr. 1997; 51: S3-7.

2 Caspersen CJ, Powell KE, Christensen GM. Physical activity, exercise and physical fitness: definitions and distinctions for health-related research. Public Health Rep. 1985; 100: 12631.

3 ICC/ESOMAR. International Code of Marketing and Social Research Practice. Paris, Amsterdam: ICC/ESOMAR, 1995.

4 Barnett V. Sample Survey: Principles and Methods. London: Arnold, 1991.

5 Kish L. Survey Sampling. New York: Wiley, 1965.

6 Kent R. Sampling cases. In: Kent R, ed. Marketing Research in Action. London: Routledge, 1993; 53.

7 Statistical Office of the European Communities. Statistics in Focus. Population and Social Conditions. Luxembourg: Eurostat Yearbook, 1996.

8 Hill A, Roberts J. Body mass index: a comparison between self-reported and measured height and weight. J. Public Health Med. 1998; 20: 206-10.

9 Istituto Nazionale di Statistica. Multipurposes Survey 1994. Rome: ISTAT Roma, 1996.

10 Engstrom LM, Ekblom B, Forsberg A, Koch M, Seger J. Livsstil-Prestation-Hälsa. Motionsvanor, fysisk prestations förmåga och hälsotillstånd bland svenska kvinnor och män I åldrarna 20-65 år. Stockholm: FOLKSAM, 1993.

11 Patterson SM, Krantz DS, Montgomery LC, Deuster PA,
Hedges SM, Nebel LE. Automated physical activity monitoring validation and comparison with physiological and self-report measures. Psychophysiology 1993; 30: 296-305.

12 Klesges RC, Eck LH, Mellon MW, Fulliton W, Some GW, Hanson CL. The accuracy of self-reports of physical activity. Med. Sci. Sports Exerc. 1990; 22: 690-7.

13 Gionet NJ, Godin G. Self reported exercise behavior of employees: a validity study. J. Оссир. Med. 1989; 12: 969-73

\section{Appendix 1: Project Management Group}

$\begin{array}{ll}\text { Austria } & \text { Professor Dr Kurt Widhalm } \\ & \text { Dr Beatrice De Cruz } \\ & \text { Dr Karin Greger } \\ \text { Belgium } & \text { Dr Anne-Marie Remaut de Winter } \\ \text { Denmark } & \text { Dr Soren Damkjaer } \\ & \text { Dr Knud Larsen } \\ \text { Finland } & \text { Dr Raimo Lappalainen } \\ \text { France } & \text { Dr Ismène Giachetti } \\ \text { Germany } & \text { Professor Franz Zunft } \\ & \text { Dr Dietlinde Friebe } \\ \text { Greece } & \text { Professor Anthony Kafatos } \\ & \text { Mrs Irine Markatji } \\ \text { Ireland } & \text { Dr Joanna Moschandrea } \\ & \text { Professor Mike Gibney } \\ \text { Italy } & \text { Dr John M Kearney } \\ \text { Luxembourg } & \text { Ms Sinéad McElhone } \\ & \text { Professor Amleto D'Amicis } \\ \text { Netherlands } & \text { Dr Anette Schmitt } \\ \text { Portugal } & \text { Dr Sylvie Paquet } \\ \text { Spain } & \text { Dr Cees de Graaf } \\ \text { Sweden } & \text { Professor Maria Daniel Vaz de Almeida } \\ \text { UK } & \text { Professor J Alfredo Martinez } \\ & \text { Professor Lars Magnus Engstrom } \\ & \text { Dr Liz Rogers }\end{array}$

\section{Participants}

Belgium

Ireland

Netherlands

Northern Ireland

UK

Mr Bart van Beeck
Dr Mary Kearney
Mr Michael McDonagh
Dr Klaas Westerterp
Dr Barbara Knox
Dr Susan Jebb

\section{Industry}

Coca-Cola

Golden Vale plc

Greencore

Group Danone

Guinness Ireland

Kraft Jacob Suchard

Mars Confectionery

Nestlé

Pepsi-Cola

Pfizer GmbH

Unilever

Dr Sophie Castell
Mr Conor Hyde
Dr Alastair Morton
Dr J Michel Antoine
Mr Peter Nash
Dr Els Rogiers
Ms Ann West
Dr Edward Fern
Dr Carol Shively
Dr Rainer Gildeggan
Dr Onno Korver

Dr Sophie Castell

Mr Conor Hyde

Dr J Michel Antoine

Mr Peter Nash

Dr Els Rogiers

Ms Ann West

Dr Edward Fern

Dr Onno Korver 
Appendix 2: Market research organizations

Austria

Belgium

Denmark

Finland

France

Germany

Greece
Ireland

Italy

Luxembourg

Netherlands

Portugal

Sweden

Spain

UK
MRBI Ltd

ASM Srl

ILReS

Intomart bv

Euroteste

GfK Sverige AB

EMER GfK

RSGB 